\title{
EXTREME HYPERSENSITIVENESS TO COW'S MILK PROTEIN IN AN INFANT.
}

BY

\author{
W. M. CUMMING, M.D., Ph.D., D.P.H., \\ Medical Superintendent, Bradford City Sanatorium, Grassington.
}

Hypersensitiveness to cow's milk is a not uncommon cause of asthma, eczema and allied anaphylactic phenomena in adults, but very few cases of its occurrence in infants appear to have been described.

Park $^{1}$ reports the case of a breast-fed infant which, at the age of six weeks was given a little cow's milk and which, after three or four hours, vomited, became collapsed, and later had diarrhœa. The child was desensitized by the mouth with gradually increasing doses beginning with 0.0001 c.cm. until large quantities of milk could be tolerated. Weill ${ }^{2}$ had a similar case which was cured by subcutaneous injection of doses of from 5 to $10 \mathrm{c.cm}$. of autoclaved cow's milk; as $\mathrm{Coke}^{3}$ points out, the autoclaving of the milk would appear to place the treatment in the category of non-specific protein therapy. Coke ${ }^{4}$ describes a case in a breast-fed infant, which was, during a short illness of the mother, fed on cow's milk (which was well borne) for 48 hours. On weaning, it was found that the child could not take cow's milk, having been sensitized by the previous isolated 'doses.'

\section{Author's CASE.}

The case to be described occurred in a breast-fed female child, aged eight months.

Family History. Neither of the parents shows any sign of, or is aware of, any protein sensitiveness in themselves. The paternal grandfather has ecze ma and asthma (probably due to a sensitiveness to his own respiratory tract infectors) of over twenty years standing, and now complicated by bronchitis and emphysema. The maternal grandmother has asthma (? cardiac). A maternal uncle has asthma which was improved by the removal of horsehair-stuffed furniture from his bed room. No further relevant history can be elicited.

Clinical Picture. The patient, female, aged 8 months, was a first child, exceedingly healthy, and above average weight.* She was fed on the breast exclusively until the age of eight months, when, as the mother was found again to be pregnant, it was decided to commence weaning. The first meal, other than from the breast, consisted of cow's milk suitably diluted with lime water and with sugar added. This meal caused, almost immediately, acute illness. The infant developed extreme pallor, with a marked local reaction as shown by redness and œdema of the lips, circumoral skin and buccal mucous membrane. With this there were very severe and typical asthma, and repeated violent vomiting. The vomit consisted at first of the ingested food, and later of thin, clear, slightly frothy mucoid fluid. Chemosis appeared later, but this was probably to be interpreted as another local reaction due to the child's rubbing her eyes with vomit-contaminated fingers: severe chemosis was noted in relatively mild attacks later, when the child had been sick in bed and so contaminated her pillow, while not under direct observation. The original attack, which lasted about an hour and a half and left the child prostrated, could not be mistaken for anything other than an anaphylactic phenomenon. Breast-fed for the remainder of the day, the child appeared normal next morning.

* The case did not occur in Sanatorium practice; there was no suggestion of a tubercular element in the condition. 
Course and Treatment. The child gave a marked positive skin reaction to cow's milk and a slight positive reaction to egg albumen. No other positive reaction was obtained.

Since so many common articles of diet contain more or less cow's milk, it seemed that this sensitiveness was likely to prove a greater handicap than most in after life, and it was therefore determined to attempt desensitization by the mouth, keeping the child meanwhile on the breast. An attempt was made at the same time to obtain a goat as a supply of milk, but very few goats are in milk at the time of year in question (winter, 1927-8), and further, on account of the then prevalence of foot-and-mouth disease, great difficulty was experienced in obtaining permission to move stock. It was not until three months later that a goat was ootained. Several proprietary foods, dried and otherwise, which have cow's milk as their basis, were tried but, as was to be expected, held no advantage over fresh cow's milk. All the likely firms were written to, but none were able to supply goat's milk in the dried form.

By experiment it was found that four drops of cow's milk diluted in two tablespoonsful of water caused only a slight local reaction and no demonstrable general reaction. This dose was given every second day and was gradually increased until, when the mother's milk began to fail, about a month later, the child was able to take a teaspoonful of milk in a day without undue reaction except for occasional sickness or slight croupy respiratory embarrassment. During this period, the child's weight remained stationary, and, while not exhibiting the sparkling health that had previously been hers, her general condition was good. In weaning, great difficulty was experienced; the main diet had to be extracts of meat, soups, etc., and, although there was no evidence of further idiosyncracies, sickness was very troublesome and the child lost $5 \mathrm{lb}$. during the ensuing two months. Rightly or wrongly, the process of desensitization was persisted in during this period, and by the end of it the child showed no marked reaction after having one ounce of milk during the day.

At about this time the child was seen by Prof. C. W. Vining, of Leeds, who kindly drew up a dietary excluding cow's milk. At about the same time a goat in milk was procured. Fed on the basis of Prof. Vining's dietary and with goat's milk as the staple food, the child's condition im. mediately showed improvement.

Once the child's nutrition was assured, it was felt that wider experimentation in the matter of dosage of cow's milk was permissible, and during the next two months it was found that the best results were obtained by giving at intervals of three or four days, just that dose which failed to cause a local reaction. At first the child was able to discriminate between the two milks, apparently by smell, certainly without tasting. She enjoyed the goat's milk, but the cow's milk had to be given as a medicine. Gradually this power of discrimination and the dislike for cow's milk appeared to be lost, although a dose of cow's milk rather too much in excess of the previous one would still cause a greater or less degree of reaction.

By the time the child was sixteen months old, her weight was again normal, her dentition, walking and talking had progressed to the extent that one would expect for her age, and, in short, except for the difficulty with cow's milk, she appeared a normal healthy child. She was at this time having 4 ounces of cow's milk during the day, every fourth day. At this stage or earlier. cream (really thick ' separated' cream) was found to be a valuable food, and was given without stint on the days on which she was not receiving cow's milk, the amount of protein in the cream being far short of the dose to cause reaction. Reactions, which were now rare, slight and generally delayed 6 to 18 hours, usually took the form of croupiness and hoarseness.

Progress thereafter was rapid and uninterrupted. At four-day intervals the dose was increased by half an ounce at a time, until the child was having 8 ounces in the day, every fourth day. Then this dose was given every day for a few days. Thereafter the dose was further increased until now, 12 months after the start of the trouble, the child is able to take as much cow's milk as she desires with no after effect.

The slight sensitiveness to egg has of late been treated, with scarcely any difficulty, on similar but less exact lines. 


\section{Discussion.}

The questions of how and when the child became sensitized are difficult. The mother states that when the child was about six months old, she gave her a sip of cream (not milk) and the juice of stewed rhubarb from her own plate. The rhubarb was blamed for the subsequent violent sickness, but from the mother's description of the condition, the writer is inclined to think that the child even at that time was sensitive. The mother is positive that with this exception she gave the child no food other than her own milk, until she was eight months old. It is possible that an officious domestic may have at some time, perhaps when the infant was crying, given her a few sips of cow's milk. The corollary suggests itself that, as a prophylactic measure, in the case at least of infants in whose family there is an 'asthmatic' strain, and whose mothers appear to have an ample supply of milk, care should be taken that prior to weaning, the child should not be allowed to have isolated mouthfuls of foreign proteincontaining foods : further, that each new protein, as it is introduced into the child's dietary, should be given at intervals of, say, not longer than a week in in order to prevent sensitization.

The account of this case is communicated in some detail, not so much on account of the rarity of the condition, as because it seems possible to the writer that lesser degrees of the same condition may be commoner than is supposed. Is it not possible that many of the cases in which there is difficulty in weaning on to cow's milk may be due to a sensitiveness of a much less degree, in which the anaphylactic signs are much less typical than in the case described? If so, it seems reasonable to suppose that they would yield to desensitization tiong the lines described above, but probably much less stringently carried out.

\section{Conclusions.}

From the experience gained in the conduct of this case, one would suggest that the following are important factors in successful treatment.

1. The diet must be adequate and of such a constitution as is easily dealt with by the infant's digestion. In this case, goat's milk was the staple food which was best borne. Further, once the desensitization is well under way, good cow's milk cream (i.e., the more nearly pure milk fat the better) is a safe and valuable food.

2. The optimum dose of cow's milk for desensitizing is that which just fails to produce a reaction which is perceptible clinically.

3. In the early stages at least, desensitizing doses should not be given too frequently, probably not more often than twice weekly. The writer feels certain that had he been able to observe the above indications from the start, desensitization could have been carried out with little or no upset of the child's health and progress ; the time required for successful treatment would probably not, however, have been appreciably shorter. 
4. In private practice it would be extremely difficult to carry out the method of desensitization outlined without the co-operation of intelligent parents or a nurse.

The writer is indebted to Dr. F. Coke for supplying him with the reference to Weill's work.

\section{REFERENCES.}

1. Park, Amer. J. Dis. Child., Chicago, 1920, XIX, 46.

2. Weill, J. de Med. de Lyon, Lyons, 1920, I, 89.

3. Coke, F., Asthma, Bristol, 1923, 183.

4. Coke, F., Ibid., 58. 